Revista de Economia Política, vol. 41, n 3, pp. 555-562, julho-setembro/2021

\title{
O futuro do capitalismo para Branko Milanović
}

\author{
The future of capitalism for Branko Milanović
}

DAVID BELTRÃO SIMONS TAVARES DE ALBUQUERQUE*

RESUMO: O artigo analisa o último livro de Branko Milanović, Capitalism, Alone: the future of the System That Rules the World, publicado em 2019, de acordo com publicações recentes. Primeiro, é apresentada a visão geral do livro. Segundo, suas relações com outras publicações semelhantes. Terceiro, a análise detalhada do livro e, finalmente, alguns de seus problemas argumentativos em relação à realidade social e econômica brasileira.

PALAVRAS-CHAVE: Capitalismo; democracia; China; Estados Unidos.

ABSTRACT: The article analyses the latest book by Branko Milanović, Capitalism, Alone: the future of the System That Rules the World, which was published in 2019, according to recent publications. First, it is presented the book's overview. Second, its relations to other similar publications. Third, the book's detailed analysis and finally, some of its argumentative problems regarding the Brazilian social and economic reality.

KEYWORDS: Capitalism; democracy; China; United States.

JEL Classification: P16; F50; P48.

Branko Milanović, em seu mais recente livro, por meio de tipos ideais em dois estudos de caso, verifica a existência e a consequência de somente um sistema socioeconômico no mundo, qual seja, o capitalismo. Haveria, todavia, diferentes tipos de capitalismo. Sociedades diferentes construíram distintas versões da mesma ideia basilar em relação ao sistema. A proposta do livro é bastante corajosa, pois não se trata de uma mera comparação entre histórias, que, quase sempre, deixa a sensação de que a narrativa é claramente enviesada, mas de inseri-las a fatores socioeconômicos e institucionais de forma complexa, a fim de desenvolver virtudes e falhas inerentes aos modelos de capitalismo.

A importância do livro é a união abrangente entre Teoria e Empiria nos estudos sobre desenvolvimento. Milanović, ex-economista-chefe de pesquisa do Banco Mundial, apresenta dados internacionais robustos sobre desigualdade de renda,

\footnotetext{
* Doutorando em Ciência Política no Programa de Pós-Graduação em Ciência Política (PPGCP) da Universidade Federal de Pernambuco (UFPE), Recife/PE, Brasil. E-mail: davidbeltrao@gmail.com. Orcid: https://orcid.org/0000-0002-0623-0435. Submetido: 18/Julho/2020; Aprovado: 20/Agosto/2020.
} 
como mostra seu livro anterior, Global Inequality: A New Approach for the Age of Globalization. No primeiro capítulo de Capitalism, Alone, no entanto, o autor evidencia ir além desse campo, para discutir as instituições e os arranjos de mercado da economia mundial contemporânea, ao identificar, no fundo, as potencialidades e falhas das teorias liberais e marxistas na abordagem do problema, especialmente na abordagem teleológica acerca de modelos de desenvolvimento.

A ideia de que as relações de produção são determinantes-chave das relações sociais e institucionais não é novidade em obras recentes. Embora as instituições sejam, sem dúvida, parte da explicação, elas deixam fenômenos inexplicáveis, onde seria necessário traçar em detalhes o suposto caminho autônomo da evolução institucional, identificando a lógica não econômica que impulsionou o processo em cada ponto e explicando a variação no tempo das transições entre países (Acemoglu e Robinson, 2012). Fatores políticos e históricos, onde a existência de um estado, definido como um governo central eficaz, sob a vigência do estado de direito e accountability, são necessários ao desenvolvimento, quando, por exemplo, o efeito de regressão autocrática a uma ditadura militar em democracias “em transição" é significativo (Fukuyama, 2014; Svolik, 2015); ou fatores econômicos, quando uma renda mais alta impediria que as democracias voltassem à ditadura, mas sem que o desenvolvimento ou a desigualdade causassem democratização, ou que, necessariamente, à medida que os estados autoritários se desenvolvam economicamente, eles fazem a transição para a democracia com mais frequência (Przeworski et al.., 2000; Piketty, 2014; Treisman, 2020). A dificuldade é estabelecer essas variáveis como interdependentes e necessárias em qualquer análise complexa de desenvolvimento econômico em uma explicação minimamente enviesada, o que o livro de Milanović responde de maneira satisfatória.

O livro é dividido em cinco capítulos. O primeiro apresenta, em termos gerais, o objeto do livro: mostrar que todo o mundo opera, hoje, com os mesmos princípios econômicos, a saber, a produção organizada para obter lucro usando mão de obra legalmente remunerada, a predominância de capital de propriedade privada, com coordenação descentralizada, e o reequilíbrio do poder econômico mundial, por um lado, entre a Europa e a América do Norte e, por outro, da Ásia, liderada pela China.

O segundo e o terceiro capítulos do livro identificam, respectivamente, os dois tipos de capitalismo, quais sejam, o "capitalismo meritocrático liberal” e o "capitalismo político", dando ênfase aos fatores e às falhas estruturais que os determinam. Os estudos de caso são representados, respectivamente, pelos Estados Unidos e pela China. A importância desses capítulos refere-se à possibilidade de influência desses modelos no Sul global, notadamente na África e na Ásia. É o caso de a competição ocorrer por concorrência, quando um sistema tenta se impor ao outro, ou por meio de cópia indireta.

O quarto capítulo observa o capital, o trabalho, o welfare state e a corrupção mundial na interação entre o capitalismo e a globalização. O quinto capítulo tenta compreender o futuro do capitalismo por meio dos valores e dos defeitos do sistema, apresentando, no fim, eventuais modelos de evolução. A ideia geral desses dois 
capítulos é desenvolver em breves tópicos o que foi apresentado nos capítulos anteriores, ao demonstrar as mudanças éticas de sociedades tecnológicas hipercomercializadas, quando o sucesso depende tão somente de valores amorais, os quais permeiam todo o comportamento humano e se espalham dos negócios às interações pessoais, modificando as relações sociais e familiares.

O "capitalismo meritocrático liberal”, representado pelas democracias ocidentais há cerca de 200 anos, é definido por meio de como os bens e serviços são produzidos e trocados ("capitalismo"), como eles são distribuídos entre indivíduos ("meritocrático") e quanta mobilidade social existe na sociedade ("liberal”) p. 12). As principais vantagens do capitalismo meritocrático liberal são o respeito à lei e o conceito de que todos têm chances iguais de sucesso, com base em seu talento e no trabalho árduo.

Uma falha sistêmica, não conjuntural, do capitalismo meritocrático liberal, nesse sentido, é que a renda do capital é extremamente concentrada e recebida principalmente pelos ricos (p. 27). O objetivo do investimento em controle político, consequentemente, é realizado não apenas para melhorar o poder econômico contemporâneo da classe dominante, mas para garantir seu domínio ao longo do tempo (p. 66). A visão amoral da vida, por meio da ética ser definida somente pela estrutura legal existente, permite a essa classe manter e reforçar sua posição dentro dos limites da lei (p. 178). O autor, por exemplo, apresenta o termo Homoploutia, onde os membros da classe dominante combinam alta renda do trabalho e do capital, o que favorece uma desigualdade de longo prazo, dentro de um contexto de falha do capitalismo meritocrático liberal enquanto sistema socioeconômico.

Essa discussão não é novidade em obras recentes, mas a inserção da crescente desigualdade como fundamento inerente a esse tipo de capitalismo aprimora essa perspectiva vis-à-vis as análises anteriores, haja vista a pouca evidência de uma ligação automática entre democracia e desigualdade de riqueza. A democracia liberal tem muitas virtudes, mas não necessariamente coloca as sociedades no caminho para uma maior igualdade de riqueza. Há autores que afirmam que a ordem política, o crescimento e a desigualdade foram moldados por fatores econômicos e militares, enquanto as instituições desempenhariam um papel nesse quadro mais limitado (Boix, 2015; Scheve e Stasavage, 2017).

A análise do "capitalismo político", para os leitores ocidentais, é a parte mais interessante da obra. Esse tem três características principais: burocracia eficiente, onde há um corpo técnico extremamente preparado; ausência do estado de direito, que favorece a corrupção e prejudica os direitos dos cidadãos; e autonomia do Estado, onde políticos administram o bem público e fazem as empresas seguirem uma linha predeterminada..

O custo de oportunidade entre corrupção, crescimento econômico e um aparato estatal preparado é, concomitantemente, o que prejudicaria esse sistema. Primeiro, há uma contradição entre a impessoalidade burocrática e a aplicação discricionária da lei. Segundo, a corrupção é endêmica ao capitalismo político, sendo uma característica sistêmica. A única maneira de as massas tolerarem esse comportamento é o equilíbrio de um perigoso trade-off entre um crescimento econômico 
exponencial e escândalos de corrupção. O autor revela-se, consequentemente, cético à viabilidade do capitalismo político servir como modelo para o Sul global, devido à impossibilidade de separação entre a política e a economia, como também à incapacidade, em processo de amadurecimento institucional, em manter um corpo burocrático relativamente impoluto em vários países.

O autor precisa justificar a escolha de qualquer interpretação de um conceito, mostrando o porquê da utilidade de um projeto de compreensão ou de mudança específica de um sistema político. $\mathrm{O}$ argumento em relação à corrupção é convincente, mas há sérias falhas que precisam ser direcionadas. A primeira refere-se à corrupção ser intrínseca ao capitalismo político. De acordo com a literatura normativa institucionalista (Philp, 2015), qualquer sistema é corrupto, variando somente em grau. $\mathrm{O}$ autor, indo ao encontro dessa literatura e a uma tendência à corrupção mundial (p. 159), não apresenta o porquê de países capitalistas políticos serem necessariamente corruptos. Pode-se, por incrível que pareça, interpretar que o comunismo estava quase livre de corrupção e que o advento do capitalismo, sobretudo na China, dada a citação no livro de Minxin Pei (2016), o produziu. Nas instituições políticas, teóricos conectam a corrupção a problemas de ação coletiva (Rothstein, 2011; Mungiu-Pippidi, 2013). Eles enfatizam que, embora as democracias desenvolvidas possam ter reduzido a incidência de corrupção convencional, sugerindo uma causalidade diferente à do autor, essas são propensas a seu próprio tipo de corrupção, que pode ser até mais insidioso. A segunda, a qual está relacionada à primeira, é como a corrupção se enquadraria na causalidade do modelo proposto. A ausência de um verdadeiro estado de direito, enquanto causa, encontraria a corrupção como mecanismo causal necessário ao desenvolvimento. O problema, na fundamentação, é ter dados que corroborem esse argumento. Em nenhum momento o autor apresenta dados sobre como a corrupção influenciaria o desenvolvimento do estado, mas somente em como ela é, de fato, muito grande, o que não é uma característica singular da China, como se pode observar por meio, por exemplo, do Global Perception Index (CPI).

$\mathrm{O}$ autor segue com as interações entre o capitalismo e a globalização, em particular, na mobilidade do trabalho, ou seja, migrações internacionais econômicas. O autor introduziu o conceito de "prêmio de nacionalidade" (citizenship premium) e argumenta que esse seria uma vantagem econômica àqueles que o possuem em países desenvolvidos, em analogia a uma economia monopolista com rendimentos crescentes de escala, haja vista a facilidade que um cidadão de determinado país teria no acesso ao sistema de bens e serviços. Não à toa, aponta o autor, um terço dos ricos no mundo possuem uma segunda nacionalidade.

Milanović defende claramente as migrações livres para o desenvolvimento econômico, mas está ciente dos possíveis efeitos adversos de curto e médio prazo das migrações livres nos Estados desenvolvidos. Imigrantes de países pobres trazem consigo práticas de instituições informais que podem prejudicar a estrutura institucional do país receptor. Os nativos, além disso, especialmente nos países com um Estado de bem-estar social desenvolvido, relutam em aceitar imigrantes, pois produzirão um fardo crescente na redistribuição de renda e na oferta de serviços. 
Haveria, nesse sentido, um trade-off entre direitos dos imigrantes e a quantidade desses (p. 143). O autor, de maneira bastante pragmática, recomenda a flexibilidade inicial dos direitos dos imigrantes, sugerindo que o direito ao trabalho em um país não deve inevitavelmente criar cidadania plena com todos os direitos decorrentes desse status. Quanto à mobilidade do capital, Milanović aceita o conceito de cadeias de valor globais, inclusive afirmando que essa é provavelmente a inovação organizacional mais importante nesta era da globalização (p. 147). Há o destaque de duas características do padrão global de cadeias de valor: a importância das instituições e a concorrência institucional para atrair investimentos estrangeiros; e incentivos embutidos para investidores para transferência de tecnologia, incluindo know how, para os países receptores, ou seja, para suas filiais nos países com perspectivas de repercussão. Para o autor, de maneira ingênua, esse novo estágio da globalização oferece novas e substanciais oportunidades de desenvolvimento para o Terceiro Mundo, já que, ao invés dos países pobres tentarem incentivar empresas estrangeiras a transferirem tecnologia, agora o proprietário dessa tecnologia pode transferir diretamente para o local offshore o máximo possível (p. 152), citando, ipsis litteris, que “"uma coalizão tácita [...] foi formada, em nível global, entre pessoas ricas nos países ricos e pessoas pobres nos países pobres” (p. 153). É no mínimo estranho essa citação em um livro que discorre sobre desigualdade.

O último capítulo deixa o leitor com muitas questões importantes sobre o futuro do capitalismo e, claro, do mundo. São discussões socioeconômicas e políticas sobre a situação atual. Segundo Milanović, ao retomar o debate do segundo capítulo, as restrições morais desapareceram no capitalismo atual e é apenas a lei que fornece algumas limitações ao interesse próprio do comportamento humano. Por exemplo, a família no moderno "capitalismo hipercomercializado" é objeto de atomização e mercantilização. A atomização refere-se "ao fato de que as famílias perderam em grande parte sua vantagem econômica com um número crescente de bens e serviços" que agora são "comprados ou alugados no mercado" (p. 187). O outro lado da atomização é a mercantilização, na qual "satisfazemos as necessidades das pessoas através da mercantilização máxima de nossos ativos, incluindo nosso tempo livre" (p. 190). O problema dessa parte é que ela é apoiada apenas por evidências circunstanciais e anedóticas para justificar o desaparecimento de restrições morais religiosas, por exemplo, quando o autor menciona um pregador Norte-americano acerca do assassinato do jornalista saudita Jamal Khashoggi (p. 180).

Há dois grandes dilemas no final do livro sobre o futuro do capitalismo. O primeiro dilema é entre a guerra ou a paz. Após uma interpretação bastante singular do início da Grande Guerra, o autor introduz os efeitos destrutivos do armamento mundial e conclui que, caso não haja destruição total, o único dilema restante será entre os dois tipos de capitalismo apresentados no livro. O segundo dilema, portanto, é entre o capitalismo meritocrático liberal e o capitalismo político.

A principal vantagem do capitalismo liberal é a democracia. Por um lado, não só a democracia é desejável em si mesma, um "bem primário", mas também tem um valor instrumental: reverter más políticas no processo de tomada de decisão. Por outro lado, "contra essas vantagens do capitalismo liberal, o capitalismo polí- 
tico promete uma administração muito mais eficiente da economia e maiores taxas de crescimento" (p. 208). A dificuldade dessa alegação é a falta de dados empíricos que o corroborem. Considerar a China como estudo de caso é muito importante, mas deve-se ter sempre em mente que normalmente ela é um outlier. Alargar os fatores de crescimento chinês para outros países menos estruturados é imprudente. Por exemplo, quanto à gestão eficiente, o próprio Milanović aponta que "o capitalismo político tem uma tendência maior a gerar políticas ruins e resultados sociais ruins que não podem ser revertidos porque os que estão no poder não têm incentivo para mudar de rumo" 1 (p. 209). Políticas malfeitas e gerenciamento eficiente da economia não são correlatos, e países em desenvolvimento podem ser atraídos ao modelo de desenvolvimento chinês na esperança de altas taxas de crescimento, mas isso não significa que terão o mesmo sucesso, haja vista não haver, até agora, causalidade entre o capitalismo político e altas taxas de crescimento.

Milanović considera dois caminhos possíveis para o futuro do capitalismo. $\mathrm{O}$ primeiro depende de como o capitalismo meritocrático liberal evoluirá para um estágio mais avançado, qual seja, o do capitalismo popular, onde, primeiro, a concentração de ganhos de capital e de riqueza seriam menores; segundo, a desigualdade de renda seria menor; por fim, a mobilidade de renda entre gerações seria maior (p. 216). O outro caminho, adverte o autor, é a convergência entre o capitalismo liberal e o político. A essência dessa convergência seria o desenvolvimento natural do que já acontece hoje, reconhece o autor, em que o capitalismo liberal se transforma em um sistema plutocrático.

A realidade brasileira, no entanto, se ajusta minimamente aos tipos ideais abordados por Milanović. A manutenção imperfeita de concentração de renda no Brasil recentemente e a influência de fatores externos na economia são causas estruturais que devem ser devidamente consideradas nas implicações sociais e políticas quando se observa esse país.

O trabalho de Pedro Herculano G. F. de Souza, por meio de fontes de dados baseadas no cruzamento de dados das declarações de Imposto de Renda (IRPF) e da Pesquisa por Amostra de Domicílios (PNAD), verifica que a redução da concentração de renda não teve um impacto tão forte na economia como se esperava e fora veiculada pelos órgãos governamentais no início do século XXI. A tese de Souza (2016) verifica, assim, que não houve nenhuma mudança substancial na concentração de renda dos mais ricos, entendido como aqueles que possuem $1 \%$ das riquezas, no Brasil. O que o autor analisa, nesse sentido, é que as mudanças mais perceptivas na estrutura de distribuição de renda no Brasil, no entanto, foram observadas no meio da pirâmide social, mas não nos mais ricos, o que afetaria sobremaneira o coeficiente de Gini (Souza, 2016). No Brasil, portanto, a regra sempre foi a concentração de renda.

O trabalho de Campello e Zucco (2016), por sua vez, observa que, uma vez observada a taxa de juros internacionais e os preços das commodities, é possível

1 Tradução nossa. 
prever o sucesso presidencial na América Latina. A democracia estaria, desse modo, profundamente atrelada a resultados econômicos que não são diretamente controláveis. Em países de baixa poupança e exportadores de commodities da América latina, os eleitores recompensam os incumbentes que governam quando as taxas de juros internacionais são baixas e os preços das commodities são altos e os sancionam quando acontece o contrário. $\mathrm{O}$ fato de o sucesso dos presidentes ser amplamente previsível pelas características da economia mundial implica que os eleitores ignoram o impacto de choques exógenos nos resultados econômicos domésticos. A importância desse estudo é em relacionar a influência de aspectos exógenos na economia nacional. A crise socioeconômica e política brasileira é resultante da interpenetração de fatores internos e externos e só teria um vislumbre de adequação ao livro de Milanović.

A força e a fraqueza do livro estão na complexidade dos temas abordados. O livro trata de um número substancial de questões, incluindo: a taxonomia do capitalismo atual; as características dos tipos identificados de capitalismo, tanto histórico quanto contemporâneo; história liberal e marxista; caminho do desenvolvimento ocidental; desigualdade; Estado de bem-estar social; corrupção; globalização; migrações e cidadania; ascensão da China e da Ásia, para mencionar alguns dos tópicos. Existe, no entanto, um custo previsível dessa abordagem: não há espaço para análises aprofundadas. Consequentemente, há trechos bastante superficiais em alguns momentos. As melhores análises do livro são dos tipos de capitalismo, quando é dedicado um capítulo para cada um desses.

A decisão ousada de Milanović, no entanto, passando de um especialista em seu campo, economia, para um universo intelectual bem mais amplo, onde debate o futuro do capitalismo com uma ampla gama de questões de políticas públicas, e por meio de análises históricas e socioeconômicas, deve ser louvada. Ele fornece muita reflexão, especialmente para analistas e tomadores de decisão governamentais. Há uma necessidade de contemplar os problemas sociais por meio da interdisciplinaridade, sendo essa a força dessa obra. O livro abre muitas questões relevantes sobre o futuro do capitalismo, melhor dizendo, o futuro do mundo.

\section{REFERÊNCIAS BIBLIOGRAFICAS}

ACEMOGLU, Daron; ROBINSON, James A. (2012), Por que as nações fracassam: as origens do poder, da prosperidade e da pobreza. Tradução de Cristiana Serra. Rio de Janeiro, Elsevier.

BOIX, Charles. (2015), Political Order and Inequality. New York, Cambridge University Press.

CAMPELLO, D. e ZUCCO Jr., C. (2016), "Presidential success and the world economy". Journal of Politics, 78 (2): 589-602.

FUKUYAMA Francis. (2014), Political Order and Political Decay: From the Industrial Revolution to the Globalization of Democracy. New York, Macmillan.

MILANOVIĆ, Branko. (2019), Capitalism, Alone: the future of the System That Rules the World. Cambridge, The Belknap Press of Harvard University Press.

MUNGIU-PIPPIDI, Alina. (2013), “Controlling corruption through collective action”. Journal of Democracy, 24 (1):101-115. 
PEI, Minxin. (2016), China's Crony Capitalism: The Dynamics of Regime Decay. Cambridge, Belknap Press of Harvard University Press.

PHILP, Mark. (2015), “The definition of political corruption”, in Routledge Handbook of Political Corruption, Abington, Routledge.

PIKETTY, Thomas. (2014), O Capital no Século XXI. Tradução de Mônica Baumgarten de Bolle. Rio de Janeiro, Intrínseca.

PRZEWORSKI, Adam; ALVAREZ Michael E.; CHEIBUB José A.; LIMONGI, Fernando. (2000), Democracy and Development: Political Institutions and Well-Being in the World, 1950-1990. New York, Cambridge Univ. Press.

ROTHSTEIN, Bo. (2011), “Anti-corruption: the indirect "big bang” approach”. Review of International Political Economy, 18 (2): 228-250

SCHEVE, Kenneth; STASAVAGE David. (2017), "Wealth inequality and democracy". Annual Review of Political Science 2017, 20: 451-468

SOUZA, P. H. G. F. (2016) A desigualdade vista do topo: a concentração de renda entre os ricos no Brasil, 1926-2013. Tese de doutoramento, Brasília, Instituto de Ciências Sociais, Departamento de Sociologia, Universidade de Brasília.

SVOLIK, Milan. (2015), "Which Democracies Will Last? Coups, Incumbent Takeovers, and the Dynamic of Democratic Consolidation”. British Journal of Political Science, 45 (4): 715-738.

TREISMAN, Daniel (2020), "Economic Development and Democracy: Predispositions and Triggers". Annual Review of Political Science 2020, 23 (1): 241-257. 